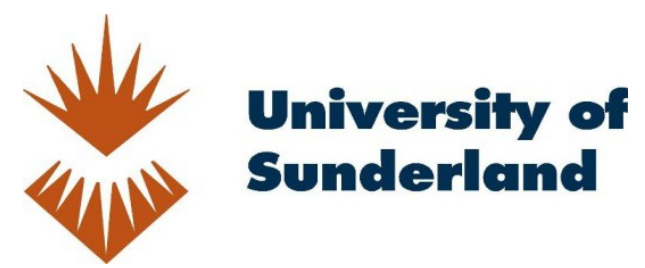

Attwood, Feona and Smith, Clarissa (2011) Investigating young people's sexual cultures: an introduction. Sex Education: Sexuality, Society and Learning, 11 (3). pp. 235-242. ISSN 1468-1811

Downloaded from: http://sure.sunderland.ac.uk/id/eprint/6097/

\title{
Usage guidelines
}

Please refer to the usage guidelines at http://sure.sunderland.ac.uk/policies.html or alternatively contact sure@sunderland.ac.uk. 
This article was downloaded by: [UNSW Library]

On: 01 November 2011, At: 23:22

Publisher: Routledge

Informa Ltd Registered in England and Wales Registered Number: 1072954 Registered

office: Mortimer House, 37-41 Mortimer Street, London W1T 3J H, UK

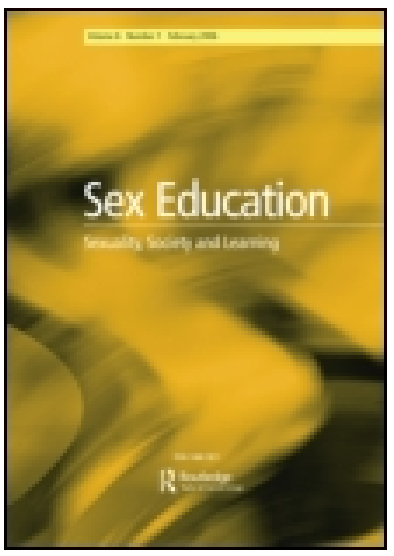

\section{Sex Education}

Publication details, including instructions for authors and subscription information:

http:// www. tandfonline.com/loi/ csed20

\section{Investigating young people's sexual cultures: an introduction}

Feona Attwood ${ }^{a} \&$ Clarissa Smith ${ }^{b}$

a Sheffield Hallam University, UK

${ }^{b}$ University of Sunderland, UK

Available online: 04 Aug 2011

To cite this article: Feona Attwood \& Clarissa Smith (2011): Investigating young people's sexual cultures: an introduction, Sex Education, 11:3, 235-242

To link to this article: http:// dx. doi.org/ 10.1080/ 14681811.2011.590040

\section{PLEASE SCROLL DOWN FOR ARTICLE}

Full terms and conditions of use: http://www.tandfonline.com/page/terms-and-conditions

This article may be used for research, teaching, and private study purposes. Any substantial or systematic reproduction, redistribution, reselling, loan, sub-licensing, systematic supply, or distribution in any form to anyone is expressly forbidden.

The publisher does not give any warranty express or implied or make any representation that the contents will be complete or accurate or up to date. The accuracy of any instructions, formulae, and drug doses should be independently verified with primary sources. The publisher shall not be liable for any loss, actions, claims, proceedings, demand, or costs or damages whatsoever or howsoever caused arising directly or indirectly in connection with or arising out of the use of this material. 


\section{INTRODUCTION TO SPECIAL ISSUE}

\section{Investigating young people's sexual cultures: an introduction}

This special issue has grown out of a small British Academy-funded project in the United Kingdom that ran from 2008 to 2010 and aimed to examine ways of developing research on young people's sexual cultures. Our backgrounds are in the area of media and cultural studies, and our own work focuses on a range of aspects of sexual culture; in particular, the production, characteristics, use and regulation of sexually explicit media texts and other sexual artefacts (see, for example, Smith 2007a, 2007b, 2010; Attwood 2009, 2010; Attwood and Smith 2010). We were interested in exploring ways of building on earlier work on young people, sex and relationships (for example, Holland et al. 1998) and more recent research (for example, Buckingham and Bragg 2004) that develops this focus in the context of a contemporary media-saturated and technology-focused culture.

We knew that some youth, health and educational agencies were expressing concern around aspects of young people's sexual cultures, based on health issues such as high rates of sexually transmitted diseases, as well as a perceived increase in young people's engagement with sexually explicit media such as pornography. Sex education and media literacy have increasingly been presented as important factors in the way young people develop sexual knowledge and form mature sexual identities. In recent years, academic work and governmental policies have increasingly highlighted both as crucial for the development of personal, social and health education, for cultural citizenship and for effective participation in society. Reports that young people were being 'sexualized' by culture were big news in a range of policy reports (American Psychological Association 2007; Australian Senate 2008; Papadopoulos 2010), books (Levy 2005; Paul 2005; Durham 2008; Oppliger 2008; Tankard Reist 2009) and in the press (see, for example, Cox 2009; Aitkenhead 2010). Yet these contained nothing in the way of convincing evidence or plausible accounts of the shifting sexual cultures of young people and seemed to be underpinned by views of sex and culture as inherently dangerous and of young people as easily corruptible and harmed. We were also aware that research that has engaged with young people and taken the study of culture seriously has come to quite different conclusions; for example, as Buckingham and Bragg (2004) show, young people engage actively and critically with the media and with ideas about sex.

Although the depiction of young people's and especially girls' sexuality as endangered by media is a very old one, now that media have become increasingly important in providing information about sex to young people and play an important part in the formation of sexual cultures, sex media have come under increased scrutiny. The 'sexualization debates' can be understood both as part of a tradition of suspicion - of media technologies, sex, and young people - and as part of a series of responses to real changes in the significance of sex in contemporary western societies, to an apparent erosion of traditional authority over sexual behaviour (Weeks 2007, 132), and to the 
presentation of sex as a matter of personal pleasure, taste and recreation. These shifts are all, in turn, part of broader developments in the way work and family are now organized, and the integration of commerce and media forms into the way we conduct our intimate lives (Bernstein 2007).

These shifts have been met with 'a flurry of regulatory controls across the globe', focused particularly on criminalizing sexual behaviours related to commerce and media (Scoular and Sanders 2010,3), and on the regulation of new online and mobile technologies (Attwood and Smith 2010). Often carried out in the name of young people and justified by widespread fears of preying paedophiles, these are now also being used to restrict young people's sexual activity, most dramatically so in recent cases where teenagers have been convicted under laws designed to prevent the distribution of child pornography (see Soderlund 2008; Goldstein 2009).

\section{Researching young people's sexual cultures}

Despite the context of heightened concern about young people's sexual cultures, the study of young people's engagements with sexual issues remains a relatively unexplored area. Research in this area is fraught with difficulties because of entrenched cultural taboos on speaking about sex that feel particularly intense in the current context of fear and anxiety. Expertise in the area is fragmented across a range of disciplines and professional sites, often with little communication between them. Our project focused on exploratory discussions with a range of specialists drawn from a variety of backgrounds and including representatives from UK agencies such as Brook, FPA, Centre for Sexual Health and HIV, and Sex Education Forum and academics working in the fields of childhood and youth studies, sexuality and sex education, and media and communication studies.

Our aims were to find out what those who work with young people thought were the particular knowledge gaps in understanding how young people think, talk and learn about sex, and what they saw as the major areas for research. We were interested in what they thought about the way institutional, cultural and social factors impact on their academic and professional work, and what they believed the main ethical and practical difficulties of such work to be. Underlying all of this was an interest in how different areas of disciplinary and professional expertise might shed light on the challenges and possibilities for developing future research into young people's engagements with sex and sexuality, and whether there was potential for developing interdisciplinary and interprofessional work on young people's sexual cultures. The following views emerged in our discussions with participants throughout the project:

- Concern about the prevalence of assumptions about young people's sexual behaviour, and the demonizing of young people (especially young women) in much contemporary discussion about young people's sexuality.

- Frustration with the impeding of work and research by the pressure to compete for funding, with bureaucracy, with fear of bad publicity and press, and with the framing of sex in unhelpful and negative ways.

- Recognition of the considerable lack of actual knowledge about young people's sexual cultures, and a particular need for qualitative work in this area.

- Desire for a greater attentiveness to ambivalence in young people's attitudes to sex, for understanding young people as producers of and participants in sexual cultures, for the problematizing of dominant terms such as 'risk', 'harm' and 'regret', and for the consideration of young people's good experiences of sex. 
Our discussions also resulted in a consensus that there was a need for the following:

- Critically informed research and policy that acknowledges the way sexual norms, ethics, representations and practices are changing, along with ideas about age appropriate behaviour.

- More holistic and grounded, rather than narrow and abstract, views of sexual health and ethics.

- Collaborative, international and interdisciplinary work in order to develop research, policy and guidelines for good practice in working with young people.

As a further way of exploring some of the issues raised in our project we were interested in editing a special issue of Sex Education on young people's sexual cultures. We chose the journal because of its commitment to international and interdisciplinary work and also because of its concern not only with sex education in the narrow sense, but with wider questions about the relation of culture to sexual behaviour and attitudes.

\section{Sexual cultures}

What do we mean by sexual cultures? We are using the term 'culture' in its broadest sense here, as Raymond Williams $(1961,57)$ did, to indicate 'a particular way of life, which expresses certain meanings and values' and which is evident 'not only in art and learning but also in institutions and ordinary behaviour'. From this point of view, cultural analysis traces the ways that meanings, values and experiences are constructed and framed in institutions, media and other forms of communication, artefacts and the practices of everyday life. 'Sexual cultures' include the many ways that sexual knowledge is constructed, how sexual values and norms are struggled over, how sex is depicted, talked about and 'done'. Of course, 'culture' is not monolithic. Although we might talk about mainstream or dominant cultural values, sexual cultures are sites of participation, negotiation, reproduction, resistance and challenge. Nor is 'culture' singular; we can talk about youth culture, parenting culture, popular culture, gay culture, online sex culture, mediated cultures, the cultures of particular sexual practitioners or specific institutional cultures - each time focusing on some particularities of a group's way of life.

In this special issue, we examine a range of aspects of 'ways of life': health policy, sex and relationships education, sex abuse therapy, television production, sport, Internet use, and the production and consumption of commercial goods and media. Some articles are firmly located in terms of place: Raffaella Ferrero Camoletto's study is of first experiences of sex in Italy, while others are more wide-ranging and comparative such as Dafna Lemish's work on television producers from around the world. The special issue also raises questions about who we might count as young people; the groups under discussion vary in terms of their actual ages, and, as a number of discussions make clear, when 'young people' are invoked it is not always an actual group of people that is being referred to, but an idea of youthfulness, and often of innocence that must be protected. As Lee Edelman has noted $(2004,12-13)$, 'the child' often stands for the future of the culture itself, and this is why it acquires such significance and arouses such strong feeling.

We begin with two articles that consider the management of young people's sexual cultures in therapeutic and health frameworks. In the first of these Anne-Marie Grondin discusses how child sexual abuse therapeutic intervention programmes in North America operate as lessons in sex education, requiring the young people they treat to adopt a 'injured' 'victim' status and to acknowledge the sexual encounter that led them to therapy as a harmful one, even if this does not fit with their own experiences, views or feelings. 
In the process, young people are constructed as innocent and vulnerable, abuse is constructed as an illness that must be treated by experts, and the power imbalance between expert and client, adult and child, is reinforced. Most importantly, this process, set up to aid young people, works to reinforce the idea that they lack power and control, thereby reproducing the conditions that make them vulnerable in the first place. The article shows how constructionist and post-structuralist approaches may be useful as starting points for transcending this impasse and thinking 'outside the box', providing a point from which to make sense of 'the box' and to begin to acknowledge children's own accounts of their experiences.

In the following article, Eleanor Formby shows how young lesbian, gay, or bisexual (LGB) British people learn about, discuss and practice 'healthy' sex, and how a view of a dominant straight sexual culture, constructed within the health institutions that serve them, is passed on by health and education providers. Particular kinds of knowledge are produced in these settings; many participants express a biomedical view of sexual health, focused on avoiding infection and downplaying broader concerns about safety and harm, or subscribe to the belief that sexual risk is largely linked to the bodies of 'other' age groups and ethnicities; views that obviously impact on their sexual practices. At the same time, a lack of engagement with the specific needs and priorities of LGB young people serves to restrict their access to the services that are provided, rendering them invisible and marginal. The article shows a number of different aspects of sexual culture - a mainstream health culture that meets some but ignores others of LGB young people's priorities, and which in addition positions their culture as 'other'; the differences within young people's sexual cultures - for example, the contrasting approaches to safer sex by lesbians and gay men and the broader national context in which a 'British' difficulty of talking about sex may impact on health provision.

The second group of articles focuses on media, commerce and technology: aspects of culture that currently occupy the centre-stage of concern in discussions of young people's well-being. Dafna Lemish examines the views of television producers from around the world on the way sex is and should be represented in 'quality' television. Despite their perception that commercial mass media are thoroughly sexualized, sex continues to be something of a taboo in quality television produced for young people and although these professionals see themselves as responsible for providing a 'healthy' view of sex, there are clear limits to what they feel able to do. While producers and programmes from the Netherlands and Nordic countries are regarded by their peers as very open and direct about sex, elsewhere the discussion and representation of sex is 'culturally inappropriate'. Indeed in most countries it is seen as more acceptable to focus on portrayals of romance rather than sex, or to represent sex only if it involves an issue of morality or has negative consequences such as teenage pregnancy. Homosexuality remains largely invisible. The result is a quite contradictory set of portrayals of sex in countries where conservative locally produced programmes are shown alongside more commercial and explicit portrayals, both set against what is otherwise a 'void' in representation.

The underlying concern about sex and commerce that Lemish notes in her article is taken up in more detail in the following discussion by Sara Bragg, David Buckingham, Rachel Russell, and Rebekah Willett. This considers commercial marketing and media, focusing on 'goods' such as clothes, toys and other branded material. Surveying existing reports on sexualization, the authors argue that these are dominated by approaches that entirely ignore what we have learnt about the way cultural meaning is produced and the importance of both context and interpretation. Their own research, carried out for the Scottish Parliament (Buckingham et al. 2010), reveals a much more complex picture of 
the ways in which young people are growing up - more slowly perhaps in taking on the adult roles and responsibilities than they might have done in the past, but much more quickly in terms of developing self-image, self-expression and skills around consumption. They found that sexualized goods are not as prevalent as is often claimed, although the blurring of boundaries between goods for adults and young people and the fact that children do not confine themselves to spaces reserved for them mean that questions about targeting and access are complicated. Furthermore, the meanings given to those goods are produced in a complex way so that an item might be 'too much' or 'just right' for one young person or parent, or mean something different depending on the context of its use. This can be seen most clearly in the discussions about the controversial Playboy logo, often seen as emblematic of sexualized culture but interpreted in a variety of ways here as disrespectful to women, as a 'cute' fashion image, as 'adult', as 'childish', or as 'tacky'. The use of an approach that involves listening to parents and children - who give more nuanced and thoughtful accounts in this project than do many reports on sexualization reveals a much more complex picture that politicians, educationalists and health providers will need to take into account if their policies are to have any relevance or success.

The next piece by Liza Tsaliki examines a particularly sensitive area of concern about contemporary young people's sexual cultures; their encounters with online pornography. In public discussions of this issue, familiar anxieties based on a much older view of sexual knowledge as harmful and the media as corrupting appear to have intensified because of the growing accessibility of sexual media of all kinds online. The article examines what appears to be a growing gulf between young people and adults where most young people say they have encountered porn - and those with the privacy to do so are more likely to seek it out - but almost all of their parents believe that they have not. It draws on the EU Kids Online project on young people and new technology (see Livingstone and Haddon 2009), and in particular on the study Greek Kids Go Online. It focuses on the question of 'harm', showing that although fears about harm are the precondition for most of the interest in young people's use of new technology, research tends not to find evidence of this. Some young people are clearly offended by porn: reporting being upset or disgusted by porn they have encountered online. However, the article raises a number of questions about what this means for the young people themselves and how we might weigh this evidence against the larger project's findings that both opportunities and risks go hand in hand with young people's increased Internet use and the development of their Internet skills.

The question of risk is taken up by Clare Bale in her article, which argues that sexual health policy in the United Kingdom draws not only on a view of media engagement as a matter of 'exposure' and 'effects', but also on a view of sexual practice as essentially 'risky' - framings that present young people as endangered and passive in their relation to the world. The article draws on a series of interviews with young people to demonstrate that rather than being 'exposed' to sexually explicit material, young people often seek it out, and that, rather than being harmed by their 'risky' experiences with media and with sexual practices, they learn from these and use them to develop opinions and capabilities. Concluding that we should move away from a view of sex and the media as essentially dangerous towards one that emphasizes young people's engagement with both as means of exploring the world, the article argues that approaches that foreground harm and risk rather than rights are likely to close down avenues for research and to disadvantage young people, especially young women.

Raffaella Ferrero Camoletto also focuses on young people's talk about sex, this time examining the way young Italian people account for their first experiences of sexual intercourse, showing the particular scripts that are commonly employed and how they take 
up and manage these cultural 'tools' in a country where young people are likely to live with their parents till they marry, and where there is a strong emphasis on sexual respectability for women. Identifying four key scripts - romantic, pragmatic, dramatic and comic - the article shows how young people often follow scripts shaped by a double standard, with young men emphasizing desire and emotional detachment and young women romanticizing sex. Yet it is the use that particular scripts are put to that is of real interest here. Some young people 'do' these scripts differently; the use of a comic script seems to provide a way of talking about sex in a more equal way, while combining different scripts suggests a use of tactics to negotiate gendered ideals around sexuality. The article concludes that researchers need to pay more attention both to what people do with the cultural resources they have to hand and to the contexts within which these emerge and which frame them.

The final two articles - by Clarissa Smith and Feona Attwood, and by Kath Albury, Moira Carmody, Clifton Evers, and Catharine Lumby - discuss two recent instances where the sexual practices of young people have come under scrutiny. In the first of these we discuss the UK Home Office contribution to the debate about sexualization in its 2010 review. We show how, while the review presents itself as an academic piece of work, it is intellectually incoherent and incompetent, and we argue that it can be better understood as part of a series of 'laments', rhetorical accounts and visceral responses to young people's sexual cultures that may begin by trying to protect young people but end by misrepresenting their cultures and denying their rights. These accounts also refuse to admit young people's voices into the debate, a strategy that is explicitly rejected in the second article that describes the 'Playing By The Rules' project, which designed workplace training for young National Rugby League players in Australia, aimed at preventing sexual violence and promoting ethical sexual interactions between young people. Whereas the UK Home Office report was inspired by concern about young women's behaviour as part of a campaign to end violence against women and girls, the 'Playing By the Rules' project was developed in response to public allegations of assault by the Sydney Bulldogs Rugby League team that were widely covered in Australian media in 2004, and which depicted young men as thugs and rapists. The project drew on Foucault's ethical model of 'care of the self, care of the other' $(1990,1997)$, emphasized ethical sexual decision-making, engaged with scholarly work on masculinities which argues that these are socially constructed, culturally diverse and subject to change, took into account the feelings, experiences and stories of young male players, and considered a variety of approaches to successful teaching and learning. Unlike the Home Office review and its poorly formulated recommendations, it provides a model of how to use academic theory and evidence to develop solutions to problems that treat young people with respect and that work.

It is all too easy in academic accounts of sex education and sexual culture to misapprehend what it is to be critical and simply be negative about 'other' approaches or about a range of 'others', whether these are media providers, parents, sex education and health workers, academics from other disciplines, or young people themselves. While we recognize the importance of a properly critical approach that is able to unpack what is at stake in the construction of particular views and practices, we also believe that it is important to acknowledge the many constraints - discursive and material - on practitioners of all kinds and to ask what academics might do, not only to produce critical accounts but to suggest ways forward that involve and support all of us who work in sex education, however broadly defined. In terms of research we believe it is important to draw on insights from different disciplines, but especially those which use methods and approaches that admit the complexity of culture in general and sexual culture in particular, are aware of the shifts and continuities in 
the way that culture, sex and young people have been viewed historically, and make more of the potential for collaborations between academics, other practitioners and young people themselves.

Above all, we believe it is vital to develop an awareness of how power imbalances between adults and young people may be reinforced, even in structures expressly designed to care for young people, and of how concerns about 'harm' and 'risk', however well intentioned, may work to control young people, refuse them rights and silence them. We believe that young people are entitled to good and comprehensive information and education about consumer, media and sexual practices, but this will only be effective if it engages with young people and their interests, interrogates what is held to be 'normal', 'natural' and 'healthy' in terms of cultural practices and age-appropriate behaviour, is ethical rather than moralistic, and is based on a commitment to young people's rights and to the broader notion of sexual rights. The work in this special issue represents the kind of approach that we believe is able to develop the effective study of and engagement with young people's sexual cultures.

\section{Acknowledgements}

The authors would like to thank the contributors to this special issue and the many people who participated in the broader British Academy project of which this is a part. These include Clare Bale, Petra Boynton, Sara Bragg, David Buckingham, David Gauntlett, Rosalind Gill, Lesley Hoggart, Roger Ingham, Mary Jane Kehily, Sonia Livingstone, and the representatives from the National Centre for Social Research, Brook, Terence Higgins Trust, the Sex Education Forum, British Pregnancy Association, Marie Stopes, Family Planning Association, and Centre for Sexual Health and HIV who were all generous with their time. The authors would also like to acknowledge the support of the British Academy, who made this project possible.

\section{References}

Aitkenhead, D. 2010. Teenage kids: Are they hooked on porn? Psychologies. http://www.psychologi es.co.uk/articles/are-teenagers-hooked-on-porn/.

American Psychological Association. 2007. Report of the APA Task Force on the sexualization of girls. Washington, DC: APA.

Attwood, F., ed. 2009. Mainstreaming sex: The sexualization of western culture. London: I.B. Tauris.

Attwood, F., ed. 2010. porn.com: Making sense of online pornography. New York: Peter Lang.

Attwood, F., and C. Smith. 2010. Extreme concern: Regulating 'dangerous pictures' in the UK. Journal of Law and Society 37, no. 1: 171-88.

Australian Senate. 2008. Inquiry into the sexualisation of children in the contemporary media environment, Parliament of Australia. http://www.aph.gov.au/Senate/committee/eca_ctte/ sexualisation_of_children/tor.htm.

Bernstein, E. 2007. Temporarily yours: Sexual commerce in post-industrial culture. Chicago, IL: University of Chicago Press.

Buckingham, D., and S. Bragg. 2004. Young people, sex and the media: The facts of life? Basingstoke/New York: Palgrave Macmillan.

Buckingham, D., S. Bragg, R. Russell, and R. Willett. 2010. Sexualised goods aimed at children. Report for the Scottish Parliament Equal Opportunities Committee. The Scottish Parliament. http://www.scottish.parliament.uk/s3/committees/equal/reports-10/eor10-02.htm.

Cox, E. 2009. Pornification of our kids. The Sun. http://www.thesun.co.uk/sol/homepage/features/ article2348839.ece.

Durham, M.G. 2008. The Lolita effect: The media sexualization of young girls and what we can do about it. Woodstock: The Overlook Press.

Edelman, L. 2004. No future: Queer theory and the death drive. Durham, NC: Duke University Press. Foucault, M. 1990. The use of pleasure: The history of sexuality: Vol. 2. New York: Vintage Books. Foucault, M. 1997. Ethics: Subjectivity and truth. Ed. P. Rabinow. New York: The New Press. 
Goldstein, L. 2009. Documenting and denial: Discourses of sexual self-exploitation. Jump Cut 51. http://www.ejumpcut.org/currentissue/goldstein/text.html.

Holland, J., C. Ramazanoglu, S. Sharpe, and R. Thomson. 1998. The male in the head: Young people, heterosexuality and power. London: Tufnell Press.

Levy, A. 2005. Female chauvinist pigs: Women and the rise of raunch culture. London: Pocket Books.

Livingstone, S., and L. Haddon. 2009. EU kids online: Final report. LSE. http://eprints.lse.ac.uk/24372/.

Oppliger, P.A. 2008. Girls gone skank: The sexualization of girls in American culture. Jefferson, NC: McFarland.

Papadopoulos, L. 2010. Sexualisation of young people review. Home Office. http://webarchive. nationalarchives.gov.uk/+/http://www.homeoffice.gov.uk/documents/Sexualisation-of-youngpeople.html.

Paul, P. 2005. Pornified: How pornography is transforming our lives, our relationships and our families. New York: Times Books.

Scoular, J., and T. Sanders. 2010. Introduction: The changing social and legal context of sexual commerce: Why regulation matters. Journal of Law \& Society 37, no. 1: 1-11.

Smith, C. 2007a. One for the girls! The pleasures and practices of reading women's porn. Bristol: Intellect.

Smith, C. 2007b. Designed for pleasure: Style, indulgence and accessorized sex. European Journal of Cultural Studies 10, no. 2: 167-84.

Smith, C. 2010. Pornographication: A discourse for all seasons. International Journal of Media and Cultural Politics 6, no. 1: 103-8.

Soderlund, G. 2008. Journalist or panderer? Framing underage webcam sites. Sexuality Research \& Social Policy 5, no. 4: 62-72.

Tankard Reist, M., ed. 2009. Getting real: Challenging the sexualisation of girls. Spinifex: Victoria.

Weeks, J. 2007. The world we have won. London: Routledge.

Williams, R. 1961. The long revolution. London: Chatto and Windus.

Feona Attwood

Sheffield Hallam University, UK

Email: f.attwood@shu.ac.uk

Clarissa Smith

University of Sunderland, UK 